\title{
Research on the changes in balance motion behavior and learning, as well as memory abilities of rats with multiple cerebral concussion-induced chronic traumatic encephalopathy and the underlying mechanism
}

\author{
HUAN ZHANG $^{1}$, ZHENGUANG ZHANG ${ }^{2}$, ZHEN WANG ${ }^{1}$, \\ YONGJIANG ZHEN ${ }^{1}$, JIANGYUN YU ${ }^{1}$ and HAI SONG ${ }^{3}$ \\ ${ }^{1}$ College of Forensic Medicine, Kunming Medical University, Kunming, Yunnan 650500; \\ Departments of ${ }^{2}$ Medical Imaging and ${ }^{3}$ Neurosurgery, The First Affiliated Hospital of \\ Kunming Medical University, Kunming, Yunnan 650032, P.R. China
}

Received December 1, 2017; Accepted June 14, 2018

DOI: $10.3892 /$ etm.2018.6474

\begin{abstract}
To study the effects of multiple cerebral concussion (MCC)-induced chronic traumatic encephalopathy on balance motion behavior learning and memory abilities of rats and its possible mechanism. 4MCC rat models were established by means of striking the head (4MCC group, $\mathrm{n}=15$ ), while normal Sprague-Dawley (SD) rats were used as controls (C group, $\mathrm{n}=15$ ). At 2 weeks after injury, balance beam (BB) test, beam walking (BW) test and Morris water maze (MWM) test were performed, respectively. The metabolites in brain tissues of rats, the number of glial fibrillary acidic protein (GFAP)positive cells and apoptotic cells in brain slices of rats, and the expression levels of phosphorylated tau (p-tau) and $A \beta_{1-40}$ proteins were detected. The score of rats in $4 \mathrm{MCC}$ group was significantly lower than that in $\mathrm{C}$ group $(\mathrm{p}<0.01)$. The escape latencies of rats in $4 \mathrm{MCC}$ group on the 4th-7th days during training and the time reaching the platform were significantly longer $(\mathrm{p}<0.05)$, but the residence time in the target quadrant was obviously shorter $(\mathrm{p}<0.01)$. Naphthalene acetic acid (NAA) and creatinine $(\mathrm{Cr})$ values in septal coronal section in 4MCC group were significantly lower, but choline (Cho) and myo-inositol (MI) values were obviously higher $(\mathrm{p}<0.01)$.The number of GFAP-positive cells in the hippocampal and septal areas in $4 \mathrm{MCC}$ group were significantly larger $(\mathrm{p}<0.01)$. In the hippocampal and septal areas of $4 \mathrm{MCC}$ group, the number of apoptotic cells was obviously larger $(\mathrm{p}<0.01)$, and the expression levels of $\mathrm{p}$-tau and $A \beta_{1-40}$ proteins were significantly
\end{abstract}

Correspondence to: Dr Jiangyun Yu, College of Forensic Medicine, Kunming Medical University, 1168 West Chunrong Road, Kunming, Yunnan 650500, P.R. China

E-mail: youbang1013@163.com

Key words: multiple cerebral concussion, balance motion, learning and memory higher $(\mathrm{p}<0.01)$. Thus, MCC-induced chronic traumatic encephalopathy can increase the expressions of $\mathrm{p}$-tau and $\mathrm{A} \beta_{1-40}$ proteins in the hippocampal and septal areas, leading to damage of hippocampal and septal neurons and increasing the number of astrocytes in the hippocampal and septal areas, ultimately damaging the balance motion behavior and learning, as well as memory abilities of rats.

\section{Introduction}

Cerebral concussion is a kind of mild traumatic brain injury, as well as the most common and mildest disease in primary brain injury, which has attracted widespread attention in recent years due to its high incidence and disability rates $(1,2)$. The clinical diagnostic criteria for cerebral concussion are as follows: transient disturbance of consciousness after head injury without focal neurological signs, and no abnormal primary brain injury in imaging examination (3). General cerebral concussion can be restored after one week, but injuries on numerous occasions leads to more serious learning, memory and neurological disorders (4). Cerebral concussion often occurs in intense physical activity, accounting for approximately $90 \%$ of exercise-induced brain injuries, causing headache, blurred vision, tinnitus and amnesia in patients. Recent epidemiological studies have shown that the vulnerable population of cerebral concussion has been constantly expanded $(5,6)$.

Research on cerebral concussion has mainly focused on epidemiology. However, few studies have focused on animal experiments and the injury mechanism. Hehar et al (7) effectively copied the cerebral concussion rat model using a metal simple-pendulum striking device to effectively conduct the research on the damage and related mechanism of cerebral concussion. Webster et al (8) proposed that the balance beam (BB) test and beam walking (BW) test can be used to effectively evaluate the balance motion behavior of animals, and the Morris water maze (MWM) test can be used to effectively evaluate the learning and memory abilities of animals. 
In this study, the multiple cerebral concussion (MCC) rat model was established to study the changes in balance motion behavior and learning and memory abilities of cerebral concussion rats, and its possible mechanisms was investigated via a number of detection methods.

\section{Materials and methods}

Animal feeding, treatment and grouping. A total of 30 male Sprague-Dawley (SD) rats weighing $(280 \pm 20)$ g were purchased from the Shanghai Bioray Laboratory Inc., (production license number of experimental animal: SCXK2014-0022) and fed in a specific-pathogen-free (SPF) animal room at $25^{\circ} \mathrm{C}$ under the humidity of $45-50 \%$; the sunshine/darkness time was set as $12 \mathrm{~h}$ light/dark. All animals had free access to food and water. After adaptation to the environment for one week, the rats were divided into two groups: 4MCC group $(n=15)$ and control group ( $\mathrm{C}$ group, $\mathrm{n}=15)$. All the animal experiments in the present study were approved by the Animal Ethics Committee of The First Affiliated Hospital of Kunming Medical University (Kunming, China), and all operations strictly followed the regulations of the National Institute Guide for the Care and Use of Laboratory Animals.

Rats in 4MCC group were fixed on the iron bench with the head tilted up to $45^{\circ}$, following the angle of pendulum. The pendulum was placed above the head of rats, freely fell down and hit the middle forehead. The procedure was repeated 4 times with 12-h interval, and whether the establishment of the rat model was successful was evaluated according to the criteria of cerebral concussion animal model: transient apnea for 5-15 sec during striking; transient disappearance of pain reflex, external auditory canal reflex and corneal reflex during striking; no intracranial hemorrhage; no visible brain tissue injury; no dyskinesia and abnormal reflex after consciousness recovery.

BB test. Before modeling, the rats in both groups were placed on the $\mathrm{BB}$ at $90 \mathrm{~cm}$ above the ground (the device was revised from Dixon laboratory) for training, and the standing time of rats on BB was recorded with $60 \mathrm{sec}$ as the limit; the operation was repeated 3 times for each rat, making rats in both groups stay on the BB for $60 \mathrm{sec}$ before modeling. After modeling, BB test was performed for rats in both groups, the balance latencies (BL) were recorded in detail, and the changes in balance motion behavior after cerebral concussion were evaluated.

$B W$ test. Rats were placed on a BB device (the device was revised from Dixon laboratory) made of a $90 \mathrm{~cm}$-long wooden runway at $120 \mathrm{~cm}$ above the ground, and the runway was equipped with four obstacles with the same interval. The experiments were performed under quiet conditions, and a 90-dB noise generator was installed on the beginning end of runway to stimulate the experimental rats. Before modeling, the rats received the $\mathrm{BW}$ test training, enabling them to pass through the four obstacles within $5 \mathrm{sec}$. After the establishment of cerebral concussion model, BW test was performed for the two groups of rats, followed by scoring: 1 point: rats ran from the starting point along the runway and passed through the first obstacle; 2 points: rats ran from the starting point along the runway and passed through the second obstacle;
3 points: rats ran from the starting point along the runway and passed through the third obstacle; 4 points: rats ran from the starting point along the runway and passed through the fourth obstacle; 5 points: rats ran from the starting point along the runway to the stopping point.

MWM test. MWM test device purchased from RWD Biotech was used for MWM test. The water maze was divided into 4 quadrants. The quadrant in which the target platform was located was quadrant I, followed by quadrants II, III and IV in a clockwise direction. After modeling, the rats in both groups were placed into the water maze for 7-day training: The target platform was placed at $1 \mathrm{~cm}$ below the surface of water, and the ink was added into the pool, making rats unable to see the platform. Then rats were randomly placed into the pool with $120 \mathrm{sec}$ as the limit, and the time climbing onto the platform (escape latency) was recorded. If rats could not find the platform after $120 \mathrm{sec}$, they were taken onto the platform for $30 \mathrm{sec}$, and the escape latency of rats in each group was recorded during training. On the 8th day, the test was formally carried out. The rats were placed into the pool with the back to the platform, and the motion track and escape latency of rats in the pool were recorded.

Magnetic resonance spectroscopy (MRS). After the behavior detection of rats in each group, the brain tissues of rats in each group were scanned via superconducting magnetic resonance imaging instrument (GE Healthcare, Chicago, IL, USA). After anesthesia, the heads of rats were fixed on the track with the body covered with a towel to keep warm. Under a prone position, the rats received MRS on the magnetic resonance coil (scanning site: septal coronal section; scanning parameters: pulse repetition time $=2,000 \mathrm{~ms}$, echo time $=144 \mathrm{~ms}$, pixels $=10 \mathrm{~mm} \times 10 \mathrm{~mm} \times 10 \mathrm{~mm}$ ), and the procedure was repeated for each rat 5 times. The metabolic profiling graphs were constructed using spectrum software to detect choline (Cho), creatinine $(\mathrm{Cr})$, naphthalene acetic acid (NAA) and myoinositol (MI).

Glial fibrillary acidic protein (GFAP) immunohistochemical staining. The rats were sacrificed immediately after MRI scan. After the brain tissues were removed, they were cut using the freezing microtome to obtain the $25 \mu$ m-thick brain slices in the septal coronal and hippocampal sections. The brain sections were placed onto the glass slide, followed by serial section and immunohistochemical staining using GFAP antibody (Milipore). After hydration, the water on the section was sucked dry using the absorbent paper, and the sections were placed on the staining rack, washed with distilled water 3 times ( $3 \mathrm{~min} /$ time), and then washed again with phosphate-buffered saline $(\mathrm{PBS})+0.1 \%$ Triton 3 times $(2 \mathrm{~min} / \mathrm{time})$. The oxidase blocking solution was added for reaction for $15 \mathrm{~min}$ with the lid covered, followed by washing with PBS $+0.1 \%$ Triton 3 times (3 min/time), membrane perforation using 3\% Triton X-100 for $10 \mathrm{~min}$, washing again with $\mathrm{PBS}+0.1 \%$ Triton twice. The cleaning solution was sucked dry, non-immune serum was added for $90 \mathrm{~min}$, the serum was sucked dry and GFAP antibody (diluted at 1:500) (Sigma, St. Louis, MO, USA) was added for incubation at $4^{\circ} \mathrm{C}$ overnight. The section was then washed with $\mathrm{PBS}+0.1 \%$ Triton 3 times (10 min/time), added with 
A

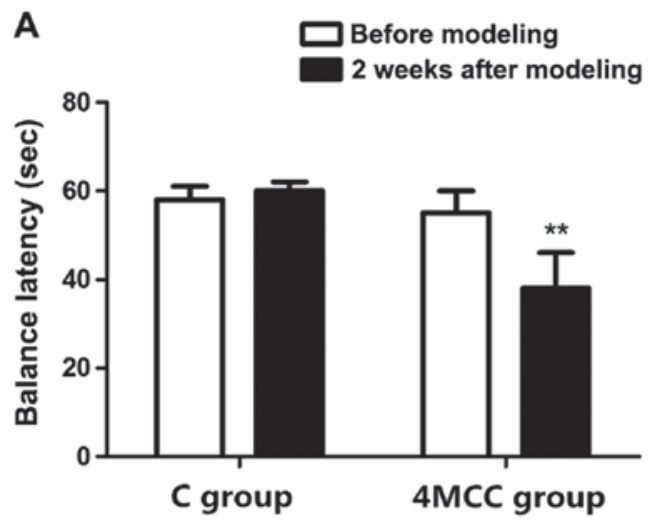

B
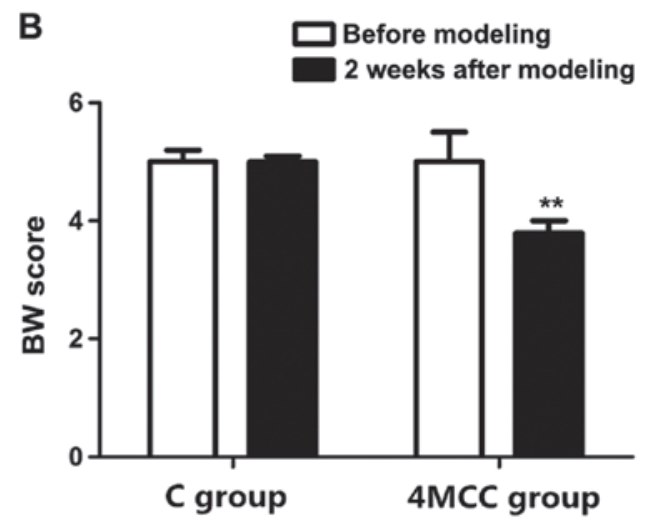

Figure 1. Evaluation of balance motion behavior via BB test and BW test. (A) BL test results. (B) BW test results; BL and BW score of rats in 4MCC group are similar to those in $\mathrm{C}$ group before modeling; at 2 weeks after modeling, BL and BW score of rats in $4 \mathrm{MCC}$ group are obviously lower than those in $\mathrm{C}$ group; ${ }^{* *} \mathrm{p}<0.01$ vs. C group.

biotin-labeled secondary antibody for incubation for $90 \mathrm{~min}$, washed 3 times ( $2 \mathrm{~min} /$ time), added with biotin-peroxidase for reaction for $12 \mathrm{~min}$, and washed with PBS $+0.1 \%$ Triton 3 times ( $3 \mathrm{~min} /$ time). Freshly-prepared diaminobenzidine (DAB) developing solution was added for color development ( 10 min). After dehydration, the sections were sealed with neutral gum and observed under a microscope (Nikon ECLiPSE 90i; Nikon Corporation, Tokyo, Japan), followed by analysis via Image. The number of GFAP-positive cells per unit visual field was calculated.

Terminal deoxynucleotidyl transferase dUTP nick endlabeling (TUNEL) apoptosis assay. The apoptosis of brain slices in septal coronal and hippocampal sections of rats in each group was determined using the TUNEL apoptosis kit (Roche Applied Science, Penzberg, Germany). For TUNEL staining, after hydration, the sections were washed with PBS. After protease $\mathrm{K}$ working solution was prepared, the sections were placed in the blocking solution for reaction for $30 \mathrm{~min}$. The paraffin sections were permeabilized with Triton X-100/sodium citrate $(0.1 \%)$ and sealed with Vectashield Hard Set (Vector Laboratories, Inc., Burlingame, CA, USA). Fluorescein isothiocyanate (FITC) was used as the fluorescent developing reagent. The number of TUNEL-positive cells was calculated in 10 visual fields.

Western blotting. The hippocampal and septal areas were separated from the brain tissues of rats in each group, added with the lysis buffer in a ratio of $1 \mathrm{~g}: 1 \mathrm{ml}$, and smashed on an ultrasonic pulverizer till no visible tissues could be seen by naked eyes, followed by centrifugation using a centrifugal machine at $9,600 \mathrm{xg}$ and $4^{\circ} \mathrm{C}$ for $10 \mathrm{~min}$. The total protein in brain tissues of the above rats was quantified using bicinchoninic acid (BCA) protein assay kit (Pierce; Thermo Fisher Scientific, Inc., Waltham, MA, USA), and added with the loading buffer to prepare the loading system in equal concentration. The sample was added into the sample sink for sodium dodecyl sulfate polyacrylamide gel electrophoresis (SDS-PAGE). After electrophoresis, the protein was transferred onto a polyvinylidene fluoride (PVDF) membrane (IPVH00010; EMD Millipore, Billerica, MA, USA), and sealed with 5\% skim milk powder for $1 \mathrm{~h}$. Then the target band was cut, and rabbit anti-rat p-tau, $A \beta_{1-40}$ and glyceraldehyde-3-phosphate dehydrogenase (GAPDH) monoclonal antibodies were incubated at $4{ }^{\circ} \mathrm{C}$ overnight (1:1,000; cat. nos. ab151559, ab62658 and ab181602, respectively; all purchased from Abcam, Cambridge, MA, USA). The band was removed, washed with Tris-buffered saline Tween (TBST) 3 times ( $5 \mathrm{~min} /$ time), incubated by horseradish peroxidase-conjugated secondary goat anti-rabbit polyclonal antibody (1:600; cat. no. AGPS002-91C; Shanghai Yihyson Biological Technology Co., Ltd., Shanghai, China) at room temperature for $2 \mathrm{~h}$ and then washed with TBST 3 times ( $5 \mathrm{~min} /$ time). Then electrochemiluminescence (ECL) luminescent liquid was added for development in the dark and the corresponding protein expression levels were analyzed via p-tau/GAPDH and $\mathrm{A} \beta_{1-40} / \mathrm{GAPDH}$.

Statistical analysis. Data in this study were presented as mean \pm standard deviation, and processed using Statistical Product and Service Solutions (SPSS) 19.0 software (SPSS Inc., Chicago, IL, USA). Student's t-test was used for the intergroup comparison. Chi-square test was used for the enumeration data. Analysis of variance and SNK post hoc test were used for the comparison among groups. $\mathrm{P}<0.05$ indicated that the difference was statistically significant.

\section{Results}

Evaluation of balance motion behavior via BB test and BW test. Changes in balance motion behavior of rats after MCC were evaluated via $\mathrm{BB}$ test and $\mathrm{BW}$ test. The results showed that the BL of rats in $4 \mathrm{MCC}$ group was similar to that in $\mathrm{C}$ group before modeling, and they could stay on the BB for $60 \mathrm{sec}(\mathrm{p}>0.05)$. At 2 weeks after modeling, the BL of rats in 4MCC group was significantly shorter than that in $\mathrm{C}$ group $(\mathrm{p}<0.01)$. The BW test revealed that the score of rats in 4MCC group was similar to that in $\mathrm{C}$ group before modeling ( $\mathrm{p}>0.05$ ), but the score of rats in 4MCC group was obviously lower than that in $\mathrm{C}$ group $(\mathrm{p}<0.01)$ (Fig. 1).

Evaluation of learning and memory abilities via MWM test. Changes in learning and memory abilities of rats after MCC were evaluated via MWM test. Rats received the training for 7 days at 2 weeks after modeling. The results showed that the 

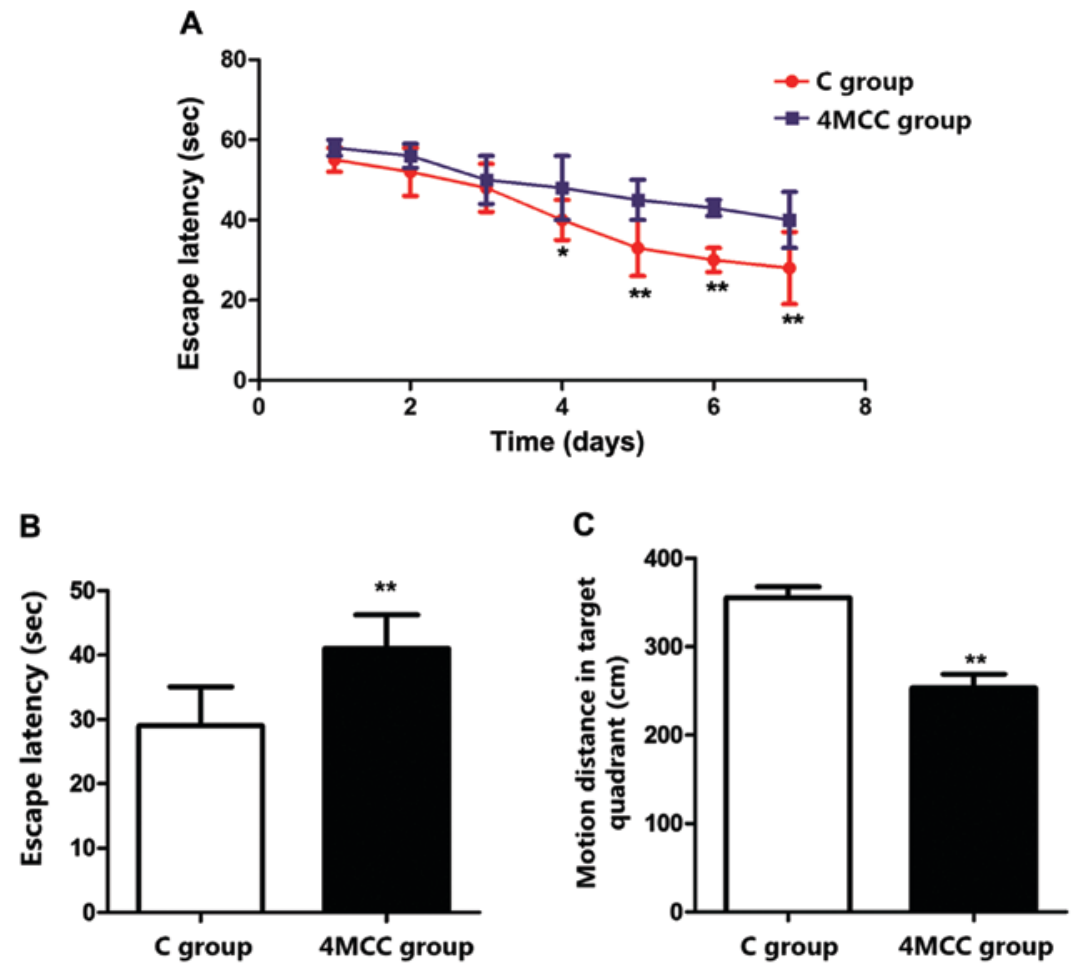

Figure 2. Evaluation of learning and memory abilities of rats via MWM test. (A) Escape latency of rats during training. (B) Escape latency of rats in experiment. (C) Motion distance of rats in target quadrant. The escape latencies in 4MCC group on the 4th to 7th days during training are significantly longer than those in $\mathrm{C}$ group; the escape latency in 4MCC group in experiment is obviously longer than that in $\mathrm{C}$ group; the motion distance in target quadrant in 4MCC group is significantly shorter than that in $\mathrm{C}$ group; ${ }^{* *} \mathrm{p}<0.01 \mathrm{vs.} \mathrm{C}$ group.

A

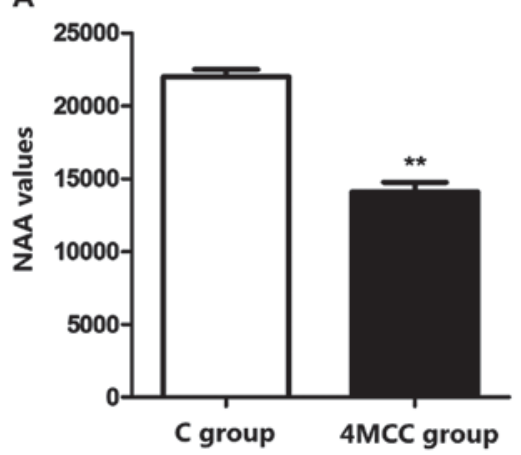

C

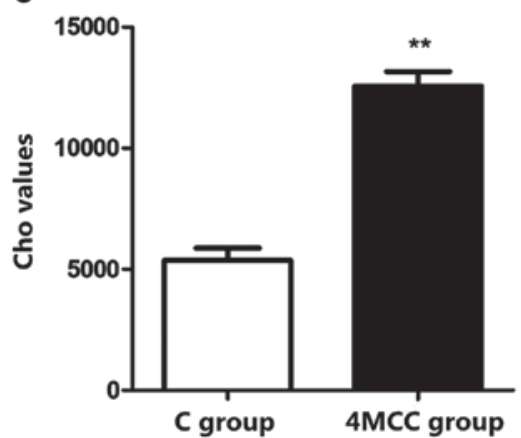

B

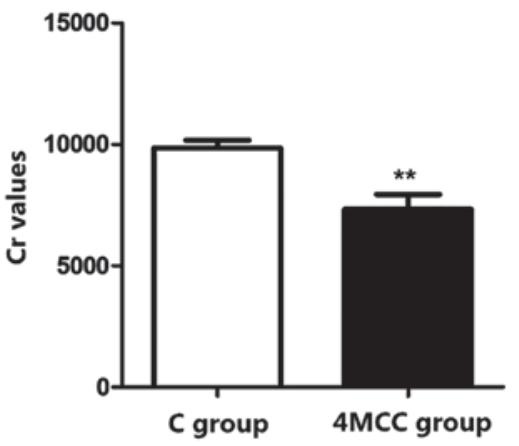

D

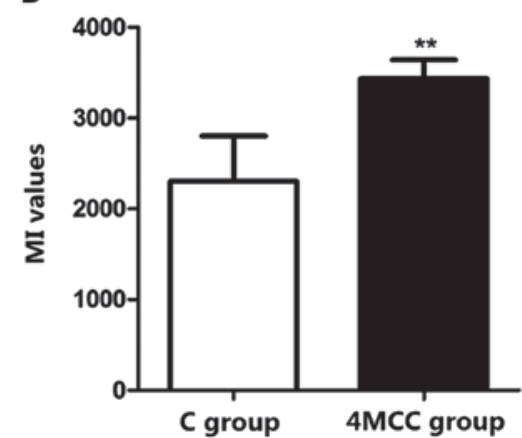

Figure 3. Detection of values of Cho, Cr, NAA and MI metabolites in septal coronal section of rats in each group via MRS. NAA (A) and Cr (B) values of rats in $4 \mathrm{MCC}$ group are significantly higher than those in C group, but Cho (C) and MI (D) values are obviously lower than those in C group; * $p<0.01 \mathrm{vs.} \mathrm{C} \mathrm{group.}$

escape latencies of rats in $4 \mathrm{MCC}$ group on the 4 th-7th days were significant longer than those in $\mathrm{C}$ group $(\mathrm{p}<0.01)$, and the escape latency of rats in 4MCC group on the 8th day was obviously longer than that in $\mathrm{C}$ group $(\mathrm{p}<0.01)$. The motion distance of rats in $4 \mathrm{MCC}$ group in target quadrant was significantly shorter than that in $\mathrm{C}$ group (p<0.01) (Fig. 2). 
A

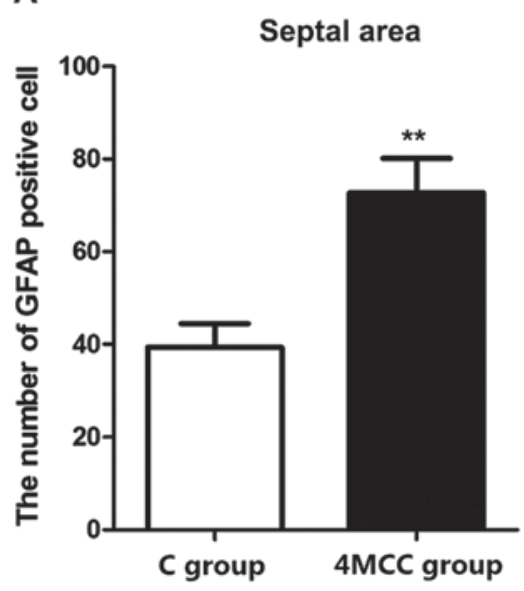

B

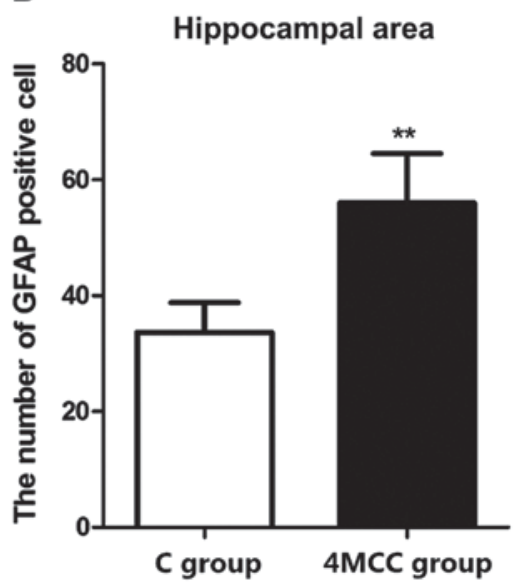

Figure 4. Detection of number of GFAP-positive cells in each group via immumohistochemical staining. (A) Septal area. (B) Hippocampal area. The numbers of GFAP-positive cells in hippocampal area and septal area of rats in $4 \mathrm{MCC}$ group are significantly larger than those in $\mathrm{C}$ group; ${ }^{* *} \mathrm{p}<0.01 \mathrm{vs}$. $\mathrm{C}$ group.

A

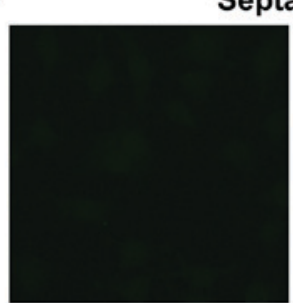

C group

B

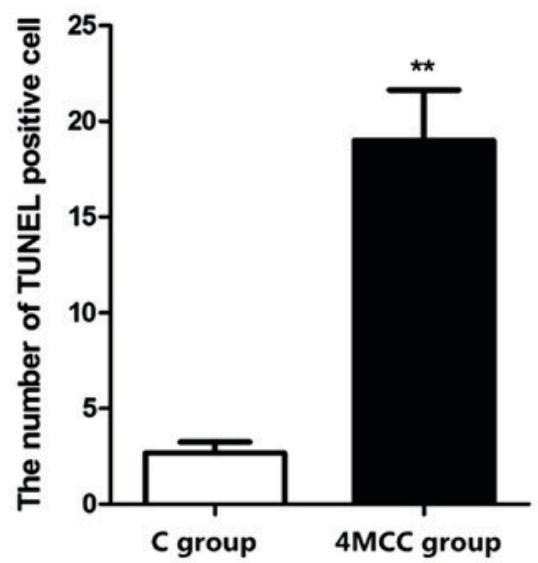

Hippocampal area

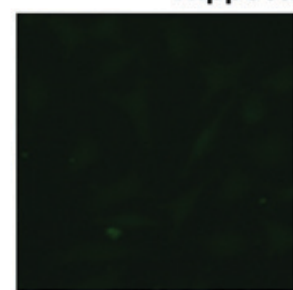

C group

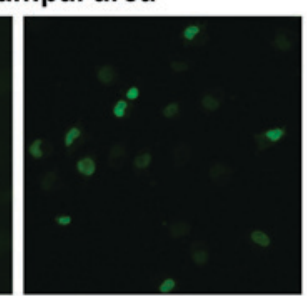

$4 \mathrm{MCC}$ group
C

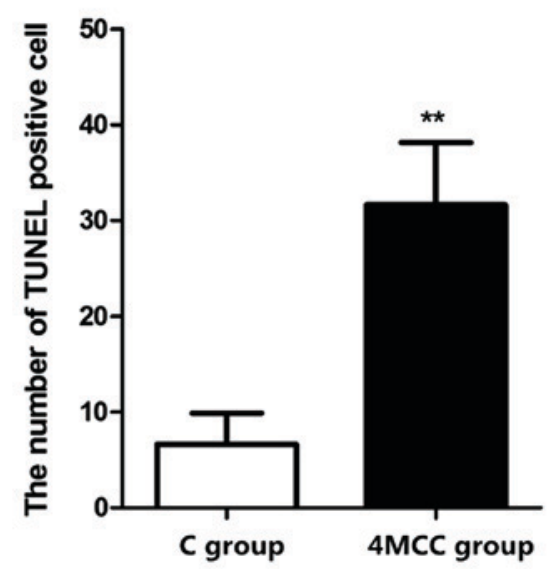

Figure 5. Detection of the number of apoptotic cells in each group via TUNEL staining. (A) Fluorescence images; green fluorescence indicates the apoptotic cells. (B) Apoptotic cells in septal area. (C) Apoptotic cells in hippocampal area; the numbers of apoptotic cells in hippocampal area and septal area of rats in $4 \mathrm{MCC}$ group are obviously larger than those in $\mathrm{C}$ group; ${ }^{* *} \mathrm{p}<0.01$ vs. C group.

$M R S$. The septal coronal section of rats in each group was scanned via MRS to measure the values of Cho, Cr, NAA and MI metabolites. The results revealed that NAA and $\mathrm{Cr}$ values of rats in 4MCC group at 2 weeks after modeling were significantly decreased compared with those in $\mathrm{C}$ group, but Cho and MI values were obviously increased $(\mathrm{p}<0.01)$ (Fig. 3).

GFAP immumohistochemical staining. The numbers of GFAPpositive cells in hippocampal area and septal area of rats in each group were detected via immumohistochemical staining.
The results revealed that the number of GFAP-positive cells in hippocampal area and septal area of rats in 4MCC group at 2 weeks after modeling was significantly larger than those in C group (p<0.01) (Fig. 4)

Detection of the number of apoptotic cells via TUNEL staining. The number of apoptotic cells in hippocampal area and septal area of rats in each group were detected via TUNEL staining. The results showed that the numbers of apoptotic cells in hippocampal area and septal area of rats in $4 \mathrm{MCC}$ group at 
A

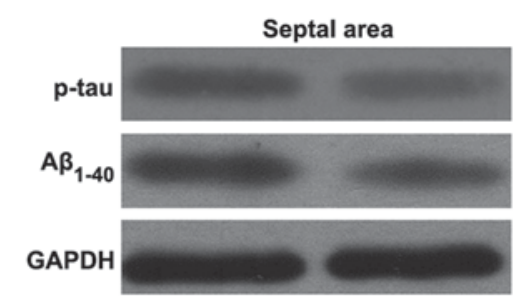

B

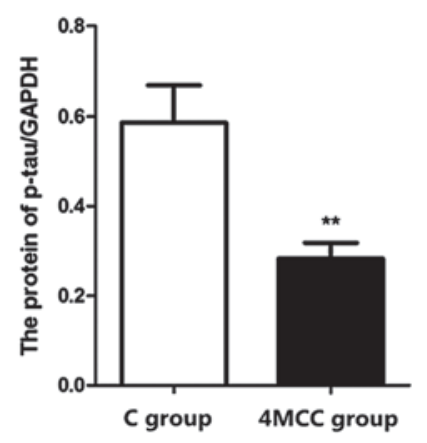

C

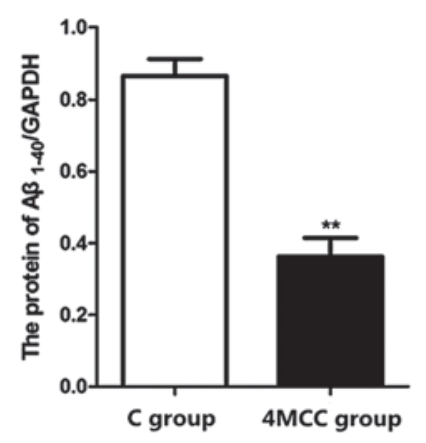

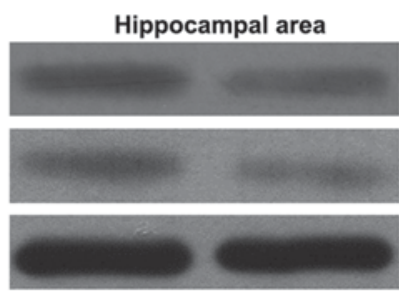

D

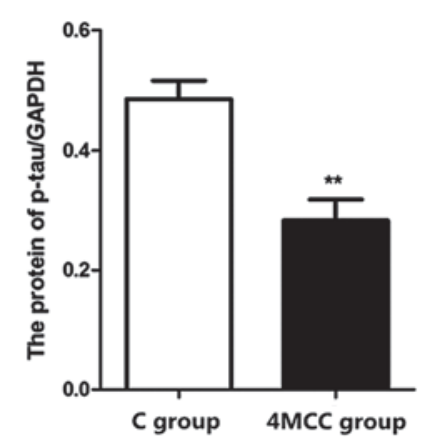

E

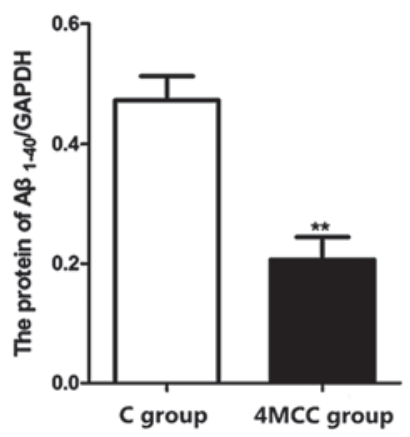

Figure 6. Detection of related protein expression levels in each group via western blotting. (A) Protein bands. (B) Statistical graph of p-tau protein in septal area. (C) Statistical graph of $A \beta_{1-40}$ protein in septal area. (D) Statistical graph of p-tau protein in hippocampal area. (E) Statistical graph of $A \beta_{1-40}$ protein in hippocampal area; the expression levels of p-tau and $\mathrm{A} \beta_{1-40}$ proteins in hippocampal area and septal area of rats in $4 \mathrm{MCC}$ group are significantly higher than those in $\mathrm{C}$ group; ${ }^{* *} \mathrm{p}<0.01$ vs. $\mathrm{C}$ group.

2 weeks after modeling were obviously larger than those in C group (p<0.01) (Fig. 5).

Detection of related protein expression levels via western blot analysis. The expression levels of phosphorylated tau (p-tau) and $A \beta_{1-40}$ proteins in hippocampal area and septal area in each group were detected via western blot analysis. The results revealed that the expression levels of $\mathrm{p}$-tau and $A \beta_{1-40}$ proteins in hippocampal area and septal area of rats in $4 \mathrm{MCC}$ group at 2 weeks after modeling were significantly higher than those in C group (p<0.01) (Fig. 6).

\section{Discussion}

Cerebral concussion caused by traumatic biological force can produce complex effects on the brain, causing a series of pathophysiological reactions and leading to rapid and transient neurological impairment. With the increasing number of trauma, it will further lead to severe damage to learning and memory abilities and balance motion behavior $(9,10)$. Benson et al (11) studied and found that when cerebral concussion in patients has not restored, the stimulation of cerebral concussion once again can lead to learning and memory and neurological disorders in patients. MCC often leads to serious neurological sequelae, seriously affecting the patients' health and even life safety (12). Through establishing the MCC rat model, Mychasiuk et al (13) simulated the process of cerebral concussion, which effectively clarified that MCC can seriously damage the learning and memory abilities. MWM test, invented by Morris, a British psychologist, is currently an internationally-accepted test for spatial recognition learning model, in which the escape latency of rats searching for the platform can effectively reflect the spatial learning ability (14). $\mathrm{BB}$ test and BW test are used to evaluate the static and dynamic balance motion behaviors of rats after injury, respectively, so as to evaluate the effect of cerebral concussion on balance motion behavior of rats (15).

In this study, MCC rat models were established via multiple striking. BB test and BW test were used to verify the effect of MCC on balance motion ability of rats. The results showed that severe damage to balance motion ability occurred in MCC rats. Kerr et al (16) found that after cerebral concussion had occurred many times, the balance ability of athletes in high-intensity collision sports significantly declines. The MWM test revealed that the escape latency of MCC rats was increased significantly, but the motion distance in target quadrant was obviously shortened. The above results indicated that MCC can reduce the learning and memory abilities of rats. Moreover, many studies in China and foreign countries have shown that patients with brain injury suffer from severe cognitive behavior disorders $(17,18)$.

MRS is a method to quantify the tissue metabolism in organs under noninvasive conditions, which is widely used in the diagnosis of a variety of metabolic diseases. The detection indexes mainly include MI, Cho, Cr and NAA (19). In this study, the changes in brain tissue metabolites in $4 \mathrm{MCC}$ rats after 2 weeks were detected via MRS. The results showed that the NAA and Cr expression levels in brain tissues in rats with cerebral concussion were significantly reduced, but Cho and MI expression levels were significantly increased, suggesting that the cerebral concussion can cause neuronal damage, leading to a significant increase in the expression level of glial cells. NAA only exists in mature nerve cells, and the neuronal loss or death can lead to a decrease in NAA; $\mathrm{Cr}$ is a standard of energy metabolism and exists in neurons and glial cells, whose expression will be reduced under pathological conditions; Cho is a precursor of acetylcholine, as well as a marker of cell membrane density and integrity, which is abundant in glial cells; MI, as a monosaccha- 
ride, is also a marker of glial cells. Cho and MI expression levels can be significantly increased in proliferation of glial cells (20). GFAP is a marker of astrocytes, and it can directly reflect the number of astrocytes. Besides, TUNEL staining can be used to label the apoptotic cells (21). In this study, GFAP was used to label the astrocytes, and TUNEL staining was performed to detect the number of apoptotic cells. The results showed that the numbers of GFAP-positive cells and TUNEL-positive cells in hippocampal and septal areas were significantly increased in rats with cerebral concussion. These results indicated that MCC can significantly increase the number of dead neural cells, and increase the glial cell expression, which are consistent with the results of MRS. Okonkwo et al (22) found that the number of astrocytes in brain tissues of patients with Alzheimer's disease and Parkinson's disease will be significantly increased, and a large number of neurons will die once the damage to learning and memory abilities occurs. This study also found that the expression levels of $\mathrm{p}$-tau and $\mathrm{A} \beta_{1-40}$ proteins in brain tissues of MCC rats were increased significantly. Both p-tau and $A \beta_{1-40}$ proteins lead to the neurodegenerative diseases, which are closely associated with learning and memory impairment.

In conclusion, MCC can lead to severe damage to learning, memory and balance motion abilities in rats, whose mechanism may be that the expression levels of $p$-tau and $A A \beta_{1-40}$ proteins in brain tissues are significantly increased due to multiple striking, resulting in neuronal apoptosis and proliferation of a large number of glial cells.

\section{Acknowledgements}

Not applicable.

\section{Funding}

This study was supported by The National Natural Science Fund (no. 81360467).

\section{Availability of data and materials}

The datasets used and/or analyzed during the current study are available from the corresponding author on reasonable request.

\section{Authors' contributions}

$\mathrm{HZ}$ and $\mathrm{ZZ}$ were responsible for animal feeding, treatment and grouping. HZ, ZW and YZ performed BB test. JY and HS contributed to MWM test. All authors have read and approved the final manuscript.

\section{Ethics approval and consent to participate}

All the animal experiments in the present study were approved by the Animal Ethics Committee of The First Affiliated Hospital of Kunming Medical University (Kunming, China), and all operations strictly followed the regulations of the National Institute Guide for the Care and Use of Laboratory Animals.

\section{Patient consent for publication}

Not applicable.

\section{Competing interests}

The authors declare that they have no competing interests.

\section{References}

1. Spira JL, Lathan CE, Bleiberg J and Tsao JW: The impact of multiple concussions on emotional distress, post-concussive symptoms, and neurocognitive functioning in active duty United States marines independent of combat exposure or emotional distress. J Neurotrauma 31: 1823-1834, 2014.

2. Gardner AJ, Howell DR, Levi CR and Iverson GL: Evidence of concussion signs in National Rugby League match play: A video review and validation study. Sports Med Open 3: 29, 2017.

3. Brooks BL, McKay CD, Mrazik M, Barlow KM, Meeuwisse WH and Emery CA: Subjective, but not objective, lingering effects of multiple past concussions in adolescents. J Neurotrauma 30: 1469-1475, 2013.

4. Ford JH, Giovanello KS and Guskiewicz KM: Episodic memory in former professional football players with a history of concussion: An event-related functional neuroimaging study. J Neurotrauma 30: 1683-1701, 2013.

5. Tator CH: Concussions and their consequences: Current diagnosis, management and prevention. CMAJ 185: 975-979, 2013.

6. Gardner AJ, Levi CR and Iverson GL: Observational review and analysis of concussion: A method for conducting a standardized video analysis of concussion in Rugby League. Sports Med Open 3: 26, 2017.

7. Hehar H, Yeates K, Kolb B, Esser MJ and Mychasiuk R: Impulsivity and concussion in juvenile rats: Examining molecular and structural aspects of the frontostriatal pathway. PLoS One 10: $\mathrm{e} 0139842,2015$.

8. Webster KM, Wright DK, Sun M, Semple BD, Ozturk E, Stein DG, O'Brien TJ and Shultz SR: Progesterone treatment reduces neuroinflammation, oxidative stress and brain damage and improves long-term outcomes in a rat model of repeated mild traumatic brain injury. J Neuroinflammation 12: 238, 2015.

9. Gioia GA: Multimodal evaluation and management of children with concussion: Using our heads and available evidence. Brain Inj 29: 195-206, 2015.

10. Barker T, Russo SA, Barker G, Rice MA Jr, Jeffrey MG, Broderick $G$ and Craddock TJA: A case matched study examining the reliability of using ImPACT to assess effects of multiple concussions. BMC Psychol 5: 14, 2017.

11. Benson BW, Meeuwisse WH, Rizos J, Kang J and Burke CJ: A prospective study of concussions among National Hockey League players during regular season games: The NHL-NHLPA Concussion Program. CMAJ 183: 905-911, 2011.

12. Brooks BL, Mannix R, Maxwell B, Zafonte R, Berkner PD and Iverson GL: Multiple past concussions in high school football players: Are there differences in cognitive functioning and symptom reporting? Am J Sports Med 44: 3243-3251, 2016.

13. Mychasiuk R, Farran A, Angoa-Perez M, Briggs D, Kuhn D and Esser MJ: A novel model of mild traumatic brain injury for juvenile rats. J Vis Exp 94: 13-28, 2014.

14. Prins ML, Hales A, Reger M, Giza CC and Hovda DA: Repeat traumatic brain injury in the juvenile rat is associated with increased axonal injury and cognitive impairments. Dev Neurosci 32: 510-518, 2010.

15. Khuman J, Meehan WP III, Zhu X, Qiu J, Hoffmann U, Zhang J, Giovannone E, Lo EH and Whalen MJ: Tumor necrosis factor alpha and Fas receptor contribute to cognitive deficits independent of cell death after concussive traumatic brain injury in mice. J Cereb Blood Flow Metab 31: 778-789, 2011.

16. Kerr ZY, Snook EM, Lynall RC, Dompier TP, Sales L, Parsons JT and Hainline B: Concussion-related protocols and preparticipation assessments used for incoming student-athletes in National Collegiate Athletic Association member institutions. J Athl Train 50: 1174-1181, 2015.

17. Huh S, Kim TW, Yang JH, Moon MH, Kim SY and Ko HY: Pharmacotherapy prescription trends for cognitive-behavioral disorder in patients with brain injury in Korea. Ann Rehabil Med 42: 35-41, 2018.

18. Berthier ML, Kulisevsky JJ, Gironell A and Lopez OL: Obsessivecompulsive disorder and traumatic brain injury: behavioral, cognitive, and neuroimaging findings. Neuropsychiatry Neuropsychol Behav Neurol 14: 23-31, 2001. 
19. Johnson B, Gay M, Zhang K, Neuberger T, Horovitz SG, Hallett M, Sebastianelli W and Slobounov S: The use of magnetic resonance spectroscopy in the subacute evaluation of athletes recovering from single and multiple mild traumatic brain injury. J Neurotrauma 29: 2297-2304, 2012

20. Lin AP, Ramadan S, Stern RA, Box HC, Nowinski CJ, Ross BD and Mountford CE: Changes in the neurochemistry of athletes with repetitive brain trauma: Preliminary results using localized correlated spectroscopy. Alzheimers Res Ther 7: 13, 2015.

21. Hazrati L-N, Tartaglia MC, Diamandis P, Davis KD, Green RE, Wennberg R, Wong JC, Ezerins L and Tator CH: Absence of chronic traumatic encephalopathy in retired football players with multiple concussions and neurological symptomatology. Front Hum Neurosci 7: 222, 2013.
22. Okonkwo DO, Yue JK, Puccio AM, Panczykowski DM, Inoue T, McMahon PJ, Sorani MD, Yuh EL, Lingsma HF, Maas AI, et al; Transforming Research and Clinical Knowledge in Traumatic Brain Injury (TRACK-TBI) Investigators: GFAP-BDP as an acute diagnostic marker in traumatic brain injury: Results from the prospective transforming research and clinical knowledge in traumatic brain injury study. J Neurotrauma 30: 1490-1497, 2013.

(i) $\Theta($ This work is licensed under a Creative Commons Attribution-NonCommercial-NoDerivatives 4.0 International (CC BY-NC-ND 4.0) License. 